\title{
EWMA Control Chart Using Repetitive Sampling for Monitoring Blood Glucose Levels in Type-II Diabetes Patients
}

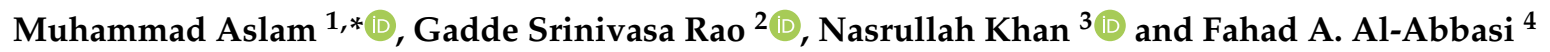 \\ 1 Department of Statistics, Faculty of Science, King Abdulaziz University, Jeddah 21589, Saudi Arabia \\ 2 Department of Statistics, The University of Dodoma, Dodoma P.O. Box 259, Tanzania; gaddesrao@gmail.com \\ 3 Department of Statistics, University of Veterinary and Animal Sciences, Sub campus Jhang, \\ Lahore 54000 Pakistan; nas_shan1@hotmail.com \\ 4 Department of Biochemistry, Faculty of Science, King Abdulaziz University, Jeddah 21589, Saudi Arabia; \\ alabassif@hotmail.com \\ * Correspondence: aslam_ravian@hotmail.com or magmuhammad@kau.edu.sa; Tel.: +966-593-329-841
}

Received: 26 November 2018; Accepted: 1 January 2019; Published: 7 January 2019

\begin{abstract}
In this paper, we discuss the application of the exponentially weighted moving average (EWMA) control chart for the monitoring blood glucose in type-II diabetes patients. We present tables for the practical use in healthcare. From the simulation results and a real example, the efficiency of the proposed chart in detecting a shift in diabetic level is compared with the existing chart. It is found that the proposed chart provides a strict method to monitor the diabetic levels in diabetes patients. From the simulation results and a real example, it is concluded that the use of the proposed chart in health care issues may reduce the risk of heart disease by monitoring diabetic levels in an effective way.
\end{abstract}

Keywords: exponentially weighted moving average chart; repetitive sampling; diabetes monitoring; statistical process monitoring

\section{Introduction}

Nowadays, control charts have many applications in public health and healthcare monitoring in hospitals and the improvement of hospital performance. The quality parameters in health care, such as the time for the examination of the patient, the number of surgical failures, the utilization of health services, and the cost of treatment and management. One of the most important procedures in statistical process control methods are control chart techniques, which are useful to improve the quality improvement in surveillance of an in-control process in health care. For example, the traditional quality aspects, like quality planning, quality improvement, and quality control, have been widely used throughout many applications (for more details see [1]).

Shewhart [2] originally proposed that control charts can also be used to understand present process performance and variation, to help achieve and confirm when a state of statistical control or the desired quality level has been reached, and to verify an improved process. The main objective to use the control charts and related methods are for understanding current process performance, achieving a consistent level of process quality and performance, monitoring for process deterioration, and reducing the amount of process variation (see [1]). The purpose of control charts is to identify the assignable causes of variation or unnatural sources of variation and remove from the process in an attempt to bring the process into statistical control. The most important purpose of statistical process control (SPC) is that the use control charts is used to initiate and evaluate quality improvement activities. According to Montgomery [3], a condition of using Shewhart control charts is that they 
are constructed according to specific methodological criteria to generate valid warning signals. The detailed information on control charts, formulas, and implementation mostly related to industrial applications can be found in Aslam et al. [4]. A more detailed study about the application of the control chart can be seen in [3]. The importance of SPC in the healthcare perspective has been addressed by different authors; for example, [1] proposed control chart for the infection monitoring, and [3,5,6] discussed the applications of the various control charts in healthcare improvement. Noyez [7] proposed the cumulative sum control (CUSUM) charts for the improved monitoring of health-related issues; Woodall [3] used the control chart for the monitoring of public health issues; control charts for the monitoring of the cardiac results were applied by [7,8]; reference [9] used the control chart tools for healthcare regulation; and Steiner et al. [1] evaluated the surgical performance using risk-adjusted cumulative sum control charts. SPC applications in healthcare are focused in several books, for example, references [10-15]; and methodological interpretation for attribute data and comparison of control charts for monitoring clinical performance using binary data are given by [16-18]. Cappon [19] also discussed the monitoring of the glucose level. Diabetes is a metabolic disease in which the blood glucose or blood sugar levels are too high, either because insulin production is insufficient, or because the body's cells do not respond properly to insulin, or both (see [19]]). As mentioned by [1], glucose comes from the diet that we eat regularly. Insulin is a hormone that helps the glucose gets into your cells to give them energy. With type 1 diabetes (T1D), that body does not make insulin. With type 2 diabetes (T2D), the more common type, the body does not make or use insulin well. Without enough insulin, the glucose stays in your blood.

The exponentially weighted moving average (EWMA) control charts are more "sensitive" to detect a small shift in the process, (see [2]). The EWMA control charts have had many applications in healthcare: in cardiac surgery [8]; reference [20] used an EWMA chart for the early detection of abnormal patient arrivals at hospital emergency department; reference [21] developed the repetitive sampling plan; worked on the modification of the EWMA chart [22]; reference [23] worked on X-bar chart using the repetitive sampling; reference [24] designed t-chart using the repetitive sampling; reference [25] worked on sign chart using the repetitive sampling. The details about repetitive group sampling plans can be seen in [20-25].

In this paper, we discuss the application of the EWMA control chart for the repetitive using the symmetry property of the normal distribution for the monitoring of blood glucose in type-II diabetes patients. We will compare the efficiency of the proposed chart with the existing control chart in terms of average run length. We presented some tables for the practical use in healthcare.

\section{Methodology}

Let us assume that the quality characteristic of interest, blood glucose level, in $\mathrm{mg} / \mathrm{dL}$ is denoted by $X_{t} ; t=1,2, \ldots$, which follows the normal distribution with mean $\mu$ and variance $\sigma^{2}$. Based on this assumption, we propose the following steps in the repetitive sampling EWMA chart [25]:

Step 1: Select a sample of size $n$ and compute the following statistics at each time $t$, where $\lambda$ is smoothing constant:

$$
E W M A_{t}=\lambda \bar{X}_{t}+(1-\lambda) E W M A_{t-1}
$$

where $\bar{X}_{t}$ is the sample mean at the time tand $E W M A_{t-1}$ is EWMA calculated at time $t-1$.

Step 2: Declare the process is stated as out-of-control if $E W M A_{t} \geq U C L_{1}$ or $E W M A_{t} \leq L C L_{1}$. Declare the process as in-control if $L C L_{2} \leq E W M A_{t} \leq U C L_{2}$. Otherwise, go to Step 1 and repeat the process.

Note here that the operational process of the EWMA chart using the repetitive sampling is same as in sequential sampling. In sequential sampling, the process continues to select a sample until the final decision about the state of the process. In the repetitive sampling, we repeat the process when in-decision at first sample. For the in-decision case, the process is repeated and a new sample is selected to make a decision about the state of the process. 
The proposed repetitive sampling EWMA control chart has two pairs of control limits $U C L_{1}$, $U C L_{2}$ and $L C L_{1}, L C L_{2}$ are given as:

$$
\begin{aligned}
& L C L_{1}=\bar{X}-k_{1} \frac{s}{\sqrt{n}} \sqrt{\frac{\lambda}{2-\lambda}} \\
& L C L_{2}=\bar{X}-k_{2} \frac{s}{\sqrt{n}} \sqrt{\frac{\lambda}{2-\lambda}} \\
& U C L_{1}=\bar{X}+k_{1} \frac{s}{\sqrt{n}} \sqrt{\frac{\lambda}{2-\lambda}} \\
& U C L_{2}=\bar{X}+k_{2} \frac{s}{\sqrt{n}} \sqrt{\frac{\lambda}{2-\lambda}}
\end{aligned}
$$

where $k_{1}$ and $k_{2}$ are control chart coefficients, $\bar{X}$ is the sample mean, and $s$ is the sample standard deviation.

Under single sampling, the probability that the process is in out-of-control the repetition and out of control $\left(P^{0}\right)$ from [25]:

$$
P^{0}=P\left(E W M A_{t}>U C L_{1}\right)+P\left(E W M A_{t}<L C L_{1}\right)
$$

The probability of repetition $\left(P_{\text {rep } 0}\right)$ for the proposed control chart is given as follows [25].

$$
P_{\text {rep }}^{0}=P\left(L C L_{1}<E W M A_{t}<L C L_{2}\right)+P\left(U C L_{2}<E W M A_{t}<U C L_{1}\right)
$$

Hence, the probability of the process being declared to be out of control $\left(P_{\text {out }}^{0}\right)$ for the proposed control chart under repetitive sampling is given as follows (see $[4,25])$ :

$$
P_{\text {out }}^{0}=\frac{P^{0}}{1-P_{\text {rep }}^{0}}
$$

The in-control ARL $\left(A R L_{0}\right)$ is given by Equation (9), which is the expected number of subgroups to be examined until the process is declared to be out of control when the process is truly in control:

$$
A R L_{0}=\frac{1}{P_{o u t}^{0}}
$$

Suppose now that the process parameter $\mu$ is shifted to $\mu_{1}=\mu+c \sigma$, where $c$ is the shift constant. Then, the probability of the process being declared to be out-of-control based on a single sample when the process is shifted is:

$$
\mathrm{P}^{1}=P\left(E W M A_{t}>U C L_{1}\right)+P\left(E W M A_{t}<L C L_{1}\right)
$$

The probability of repetition $\left(P_{r e p}^{1}\right)$ for the proposed control chart when the process is shifted is given as follows (see [4,25]):

$$
P_{\text {rep }}^{1}=P\left(L C L_{1}<E W M A_{t}<L C L_{2}\right)+P\left(\mathrm{UCL}_{2}<E W M A_{t}<U C L_{1}\right)
$$

Hence, the probability of the process being declared to be out of control $\left(P_{\text {out }}^{1}\right)$ for the proposed control chart under repetitive sampling when the process is given as follows (see $[4,25])$ :

$$
P_{\text {out }}^{1}=\frac{P^{1}}{1-P_{r e p}^{1}}
$$


The out-of-control $A R L\left(A R L_{1}\right)$ is obtained as follows:

$$
A R L_{1}=\frac{1}{P_{\text {out }}^{1}}
$$

Usually, the practitioners have the information about the parameters of the normal distribution. If parameters are unknown, they can estimate from the data.

Let $r_{0}$ be the assumed in-control $A R L$. We estimated the control constants $k_{1}$ and $k_{2}$ using Monte Carlo simulation such that $A R L_{0} \geq r_{0}$. We noted first out-of-control (run length) and repeated the process 10,000 times. We developed programming to obtain the estimates of control constants. The program is available with authors upon request. Then using Equation (13), we obtain $A R L_{1}$ based on the determined values of $k_{1}$ and $k_{2}$ for various shift values of $\mu_{1}=\mu+c \sigma$. From Tables 1-3, wherein the ARL for $r_{0}=370, c=0$ to 1.0 , and $\lambda=0.10,0.20$, and 0.30 , respectively, we observe the following behavior of $A R L_{1}$ :

1. The case of $\mu=0, \sigma=1$, that is when the process is in-control, ARL value obtained is very close to the target $r_{0}$ values.

2. As the shift $c$ increases (i.e., the process mean increases), the out-of-control ARLs decrease rapidly. A similar trend can be observed from Tables 2 and 3 whereas decreasing speed seems to get faster after $c=0.1$. When sample size increases, the values of $A R L_{1}$ decrease. It means that at the large sample size, we have a quick indication about the shift in the sugar level (see Figure 1).

Table 1. Estimated ARLs when $r_{0}=370$ and $\lambda=0.10$.

\begin{tabular}{|c|c|c|c|c|c|c|}
\hline \multirow{4}{*}{$c$} & \multicolumn{6}{|c|}{$k_{1}=3.0066 ; k_{2}=2.2356$} \\
\hline & \multicolumn{6}{|c|}{$n$} \\
\hline & 5 & 10 & 20 & 30 & 50 & 100 \\
\hline & \multicolumn{6}{|c|}{$A R L_{1}$} \\
\hline 0 & 370.00 & 370.00 & 370.00 & 370.00 & 370.00 & 370.00 \\
\hline 0.01 & 353.12 & 337.55 & 309.80 & 285.82 & 246.48 & 180.10 \\
\hline 0.02 & 309.80 & 264.89 & 202.54 & 161.53 & 111.35 & 56.53 \\
\hline 0.03 & 255.40 & 190.77 & 121.26 & 85.18 & 49.32 & 19.43 \\
\hline 0.05 & 157.38 & 91.57 & 43.43 & 25.36 & 11.59 & 3.56 \\
\hline 0.08 & 71.94 & 31.58 & 11.15 & 5.60 & 2.39 & 1.15 \\
\hline 0.1 & 43.43 & 16.54 & 5.22 & 2.64 & 1.37 & 1.02 \\
\hline 0.15 & 13.75 & 4.26 & 1.53 & 1.12 & 1.01 & 1.00 \\
\hline 0.2 & 5.22 & 1.75 & 1.06 & 1.01 & 1.00 & 1.00 \\
\hline 0.25 & 2.48 & 1.17 & 1.00 & 1.00 & 1.00 & 1.00 \\
\hline 0.3 & 1.53 & 1.03 & 1.00 & 1.00 & 1.00 & 1.00 \\
\hline 0.4 & 1.06 & 1.00 & 1.00 & 1.00 & 1.00 & 1.00 \\
\hline 0.5 & 1.00 & 1.00 & 1.00 & 1.00 & 1.00 & 1.00 \\
\hline
\end{tabular}

Table 2. Estimated ARLs when $r_{0}=370$ and $\lambda=0.20$.

\begin{tabular}{|c|c|c|c|c|c|c|}
\hline \multirow{4}{*}{$c$} & \multicolumn{6}{|c|}{$k_{1}=3.0134 ; k_{2}=1.9885$} \\
\hline & \multicolumn{6}{|c|}{$n$} \\
\hline & 5 & 10 & 20 & 30 & 50 & 100 \\
\hline & \multicolumn{6}{|c|}{$A R L_{1}$} \\
\hline 0 & 370.00 & 370.00 & 370.00 & 370.00 & 370.00 & 370.00 \\
\hline 0.01 & 369.06 & 368.13 & 366.28 & 364.45 & 360.83 & 352.05 \\
\hline 0.02 & 366.28 & 362.63 & 355.52 & 348.65 & 335.58 & 306.40 \\
\hline 0.03 & 361.73 & 353.78 & 338.77 & 324.84 & 299.79 & 249.85 \\
\hline 0.05 & 347.81 & 327.85 & 293.42 & 264.81 & 220.03 & 150.24 \\
\hline 0.08 & 317.53 & 276.78 & 217.76 & 177.24 & 125.62 & 66.17 \\
\hline 0.1 & 293.42 & 240.66 & 173.06 & 131.95 & 85.20 & 38.94 \\
\hline 0.15 & 229.96 & 160.99 & 94.11 & 62.43 & 33.31 & 11.56 \\
\hline 0.2 & 173.06 & 104.58 & 51.38 & 30.48 & 14.06 & 4.19 \\
\hline 0.25 & 127.94 & 67.88 & 28.79 & 15.61 & 6.52 & 2.00 \\
\hline
\end{tabular}


Table 2. Cont.

\begin{tabular}{|c|c|c|c|c|c|c|}
\hline \multirow{4}{*}{$c$} & \multicolumn{6}{|c|}{$k_{1}=3.0134 ; k_{2}=1.9885$} \\
\hline & \multicolumn{6}{|c|}{$n$} \\
\hline & 5 & 10 & 20 & 30 & 50 & 100 \\
\hline & \multicolumn{6}{|c|}{$A R L_{1}$} \\
\hline 0.3 & 94.11 & 44.52 & 16.66 & 8.44 & 3.40 & 1.32 \\
\hline 0.4 & 51.38 & 20.02 & 6.25 & 3.04 & 1.47 & 1.03 \\
\hline 0.5 & 28.79 & 9.65 & 2.84 & 1.58 & 1.09 & 1.00 \\
\hline 0.6 & 16.66 & 5.06 & 1.66 & 1.16 & 1.01 & 1.00 \\
\hline 0.7 & 10.00 & 2.94 & 1.23 & 1.04 & 1.00 & 1.00 \\
\hline 0.8 & 6.25 & 1.94 & 1.08 & 1.01 & 1.00 & 1.00 \\
\hline 0.9 & 4.10 & 1.45 & 1.02 & 1.00 & 1.00 & 1.00 \\
\hline 1 & 2.84 & 1.22 & 1.01 & 1.00 & 1.00 & 1.00 \\
\hline
\end{tabular}

Table 3. Estimated ARLs when $r_{0}=370$ and $\lambda=0.30$.

\begin{tabular}{|c|c|c|c|c|c|c|}
\hline \multirow{4}{*}{$c$} & \multicolumn{6}{|c|}{$k_{1}=3.0105 ; k_{2}=2.0796$} \\
\hline & \multicolumn{6}{|c|}{$n$} \\
\hline & 5 & 10 & 20 & 30 & 50 & 100 \\
\hline & \multicolumn{6}{|c|}{$A R L_{1}$} \\
\hline 0 & 370.00 & 370.00 & 370.00 & 370.00 & 370.00 & 370.00 \\
\hline 0.01 & 361.77 & 353.86 & 338.92 & 325.05 & 300.11 & 250.36 \\
\hline 0.02 & 338.92 & 312.15 & 268.43 & 234.28 & 184.55 & 115.17 \\
\hline 0.03 & 306.03 & 259.12 & 195.20 & 153.91 & 104.29 & 51.39 \\
\hline 0.05 & 230.54 & 161.76 & 94.95 & 63.23 & 33.98 & 11.98 \\
\hline 0.08 & 136.81 & 74.79 & 32.92 & 18.30 & 7.87 & 2.38 \\
\hline 0.1 & 94.95 & 45.26 & 17.17 & 8.80 & 3.59 & 1.36 \\
\hline 0.15 & 39.02 & 14.24 & 4.31 & 2.20 & 1.24 & 1.01 \\
\hline 0.2 & 17.17 & 5.31 & 1.73 & 1.19 & 1.02 & 1.00 \\
\hline 0.25 & 8.20 & 2.47 & 1.16 & 1.02 & 1.00 & 1.00 \\
\hline 0.3 & 4.31 & 1.51 & 1.03 & 1.00 & 1.00 & 1.00 \\
\hline 0.4 & 1.73 & 1.06 & 1.00 & 1.00 & 1.00 & 1.00 \\
\hline 0.5 & 1.16 & 1.00 & 1.00 & 1.00 & 1.00 & 1.00 \\
\hline 0.6 & 1.03 & 1.00 & 1.00 & 1.00 & 1.00 & 1.00 \\
\hline
\end{tabular}

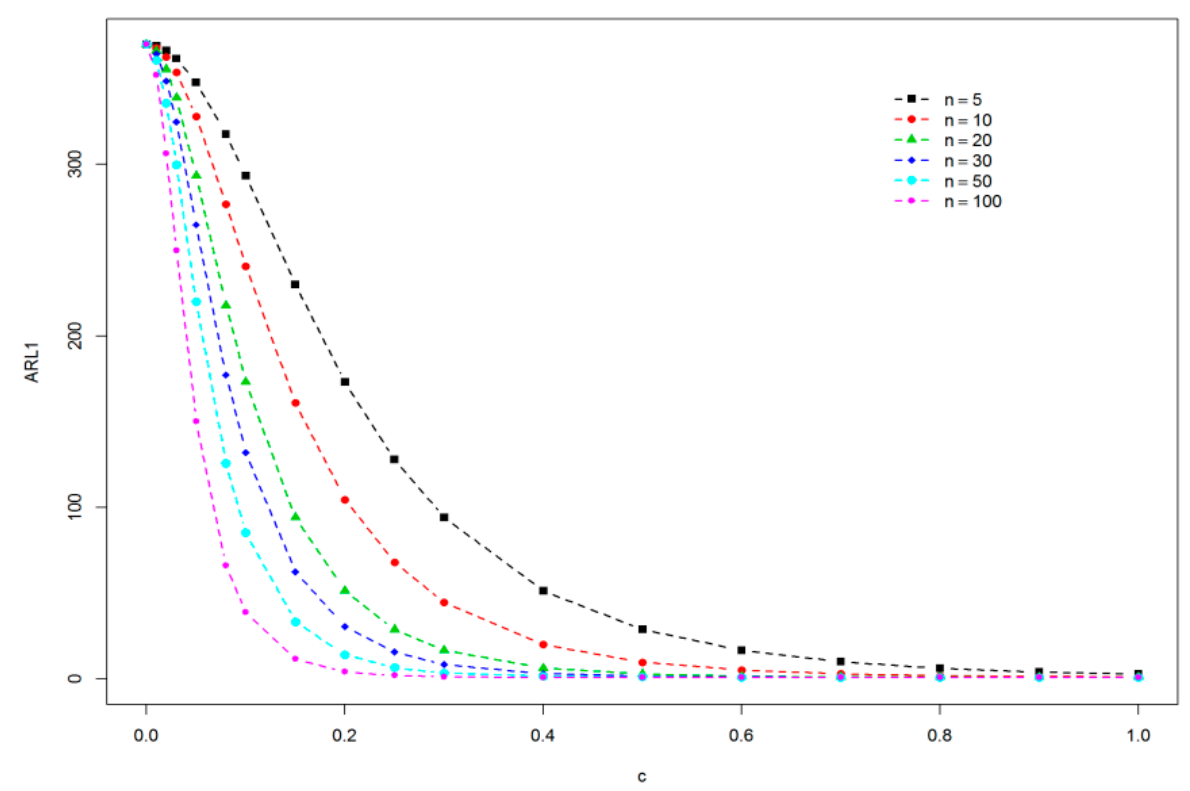

Figure 1. The proposed chart ARL1 performance for different values of $\mathrm{n}$ at $\lambda=0.10$ and $r_{0}=370$. 


\section{Case Study Results}

The diabetic health issue is a long-believed disease with major significance to world health and is now considered one of the foremost threats to human health in Saudi Arabia (see [26]). The worldwide epidemic of people with type II diabetes is mostly related to a place of living, food habits, ageing, the obesity and physical inactivity. The World Health Organization (WHO) defines diabetes as a metabolic disorder of multiple etiologies characterized by chronic hyperglycemia with disturbances of carbohydrate, fat, and protein metabolism that results from defects in insulin secretion, insulin action, or both. Rathmann and Giani [27] studied that the total number of people worldwide with type II diabetes was expected to increase from 171 million in 2000 to 366 million in 2030. A study carried out by [28] on Saudi women from Al-Khobar with the aim of examining their behaviors of eating and physical activity as well as their perceptions of body size, accepted the hypothesis that obesity is related to eating and exercise behaviors. Al-Nuaim et al. [26] confirmed that the prevalence of obesity and overweight was attributed to regional differences. Al-Baghli et al. [29] studied overweight and obesity in the eastern province of Saudi Arabia, less educated women was more subjected to obesity. Glycemic control is one of the important strategies for the management of diabetic levels as regarded by the American Diabetes Association (ADA) (see [30]). Diabetic has become one of the most common public health issues in Saudi Arabia.

As the global average prevalence of diabetes is around 10\%. A study of [31], reveals that the gulf countries appear to have a higher prevalence of diabetes than the global average. The recent rapid socio-economic development of these countries has been associated with this rising prevalence. Based on a study in 2009, the overall prevalence of Type 2 diabetes in the Kingdom of Saudi Arabia (KSA) was $30 \%$. This article is designed to study the rate of glycemic control of diabetic care hospital with type 2 diabetes in KSA. The data was collected from five patients that constitute the case study. The blood sugar level $\mathrm{mg} / \mathrm{dL}$ of each patient is checked and reported in Table 4. A drug Glucophage $500 \mathrm{mg}$ was given twice a day in first 20 weeks, $500 \mathrm{mg}$ in a day for weeks $21-30$ and then $250 \mathrm{mg}$ for a day for the weeks 31-40. Using Table 4, we constructed the Shewhart control and repetitive sampling EWMA chart to monitor the variations in the blood sugar level of patients.

Table 4. Blood sugar level (mg/dL) of patients in 2016.

\begin{tabular}{|c|c|c|c|c|c|c|c|c|c|c|c|c|c|c|c|}
\hline \multirow{2}{*}{$\frac{\text { Week }}{1}$} & \multicolumn{5}{|c|}{ Blood Sugar Level (mg/dL) } & \multirow{2}{*}{$\frac{\bar{X}}{225.4}$} & \multirow{2}{*}{$\begin{array}{c}E \boldsymbol{E} \boldsymbol{M} \boldsymbol{A}_{\boldsymbol{t}} \\
197.6\end{array}$} & \multirow{2}{*}{$\begin{array}{c}\text { Week } \\
21\end{array}$} & \multicolumn{5}{|c|}{ Blood Sugar Level (mg/dL) } & \multirow{2}{*}{$\begin{array}{c}\bar{X} \\
145.8\end{array}$} & \multirow{2}{*}{$\begin{array}{c}E W M A_{t} \\
174.0\end{array}$} \\
\hline & 370 & 175 & 193 & 192 & 197 & & & & 149 & 157 & 126 & 160 & 137 & & \\
\hline 2 & 313 & 255 & 170 & 294 & 203 & 247.0 & 207.5 & 22 & 132 & 203 & 229 & 184 & 123 & 174.2 & 174.0 \\
\hline 3 & 270 & 205 & 190 & 203 & 194 & 212.4 & 208.5 & 23 & 126 & 190 & 237 & 187 & 139 & 175.8 & 174.4 \\
\hline 4 & 190 & 221 & 177 & 173 & 171 & 186.4 & 204.1 & 24 & 143 & 204 & 200 & 245 & 187 & 195.8 & 178.6 \\
\hline 5 & 185 & 242 & 278 & 202 & 189 & 219.2 & 207.1 & 25 & 117 & 219 & 170 & 197 & 158 & 172.2 & 177.4 \\
\hline 6 & 190 & 228 & 184 & 165 & 268 & 207.0 & 207.1 & 26 & 114 & 201 & 264 & 169 & 178 & 185.2 & 178.9 \\
\hline 7 & 177 & 166 & 173 & 224 & 234 & 194.8 & 204.6 & 27 & 122 & 179 & 235 & 167 & 226 & 185.8 & 180.3 \\
\hline 8 & 175 & 239 & 268 & 198 & 176 & 211.2 & 205.9 & 28 & 134 & 213 & 182 & 137 & 269 & 187.0 & 181.6 \\
\hline 9 & 165 & 176 & 196 & 201 & 246 & 196.8 & 204.1 & 29 & 132 & 284 & 180 & 207 & 235 & 207.6 & 186.8 \\
\hline 10 & 183 & 150 & 243 & 188 & 172 & 187.2 & 200.7 & 30 & 110 & 246 & 110 & 272 & 117 & 171.0 & 183.7 \\
\hline 11 & 185 & 165 & 164 & 188 & 231 & 186.6 & 197.9 & 31 & 107 & 234 & 212 & 201 & 141 & 179.0 & 182.7 \\
\hline 12 & 177 & 189 & 178 & 186 & 186 & 183.2 & 195.0 & 32 & 125 & 220 & 225 & 113 & 214 & 179.4 & 182.1 \\
\hline 13 & 165 & 274 & 248 & 183 & 179 & 209.8 & 197.9 & 33 & 105 & 190 & 196 & 187 & 252 & 186.0 & 182.9 \\
\hline 14 & 169 & 177 & 159 & 269 & 207 & 196.2 & 197.6 & 34 & 107 & 232 & 209 & 257 & 225 & 206.0 & 187.5 \\
\hline 15 & 170 & 218 & 197 & 140 & 186 & 182.2 & 194.5 & 35 & 116 & 234 & 241 & 214 & 182 & 197.4 & 189.5 \\
\hline 16 & 155 & 170 & 206 & 155 & 176 & 172.4 & 190.1 & 36 & 118 & 189 & 194 & 183 & 164 & 169.6 & 185.5 \\
\hline 17 & 160 & 231 & 228 & 220 & 241 & 216.0 & 195.3 & 37 & 116 & 207 & 271 & 213 & 219 & 205.2 & 189.4 \\
\hline 18 & 152 & 161 & 179 & 162 & 168 & 164.4 & 189.1 & 38 & 105 & 173 & 179 & 226 & 165 & 169.6 & 185.5 \\
\hline 19 & 162 & 173 & 111 & 153 & 200 & 159.8 & 183.2 & 39 & 108 & 215 & 246 & 259 & 236 & 212.8 & 190.9 \\
\hline 20 & 165 & 196 & 173 & 168 & 158 & 172.0 & 181.0 & 40 & 109 & 281 & 134 & 200 & 232 & 191.2 & 191.0 \\
\hline
\end{tabular}

We have taken an average of five patients as our quality characteristic. Thus, in Figures 2 and 3 , an average quality characteristic has been used. Figure 2 shows the traditional control chart for monitoring of glucose levels in type II diabetic patients and Figure 3 shows the same data using the proposed control chart. From Figure 2, it can be seen that the traditional Shewhart control chart shows 
that patients sugar levels are in-control state while Figure 3 shows that the diabetic level of patients has been gone out-of-control in several occasions. We also noted some points in the in-decision area which clearly indicates the advisor to select another sample from the patient to reach on the specific decision (e.g., at 3, 4, 6, 7, 8, 9, 10, 22, 23, and 24).

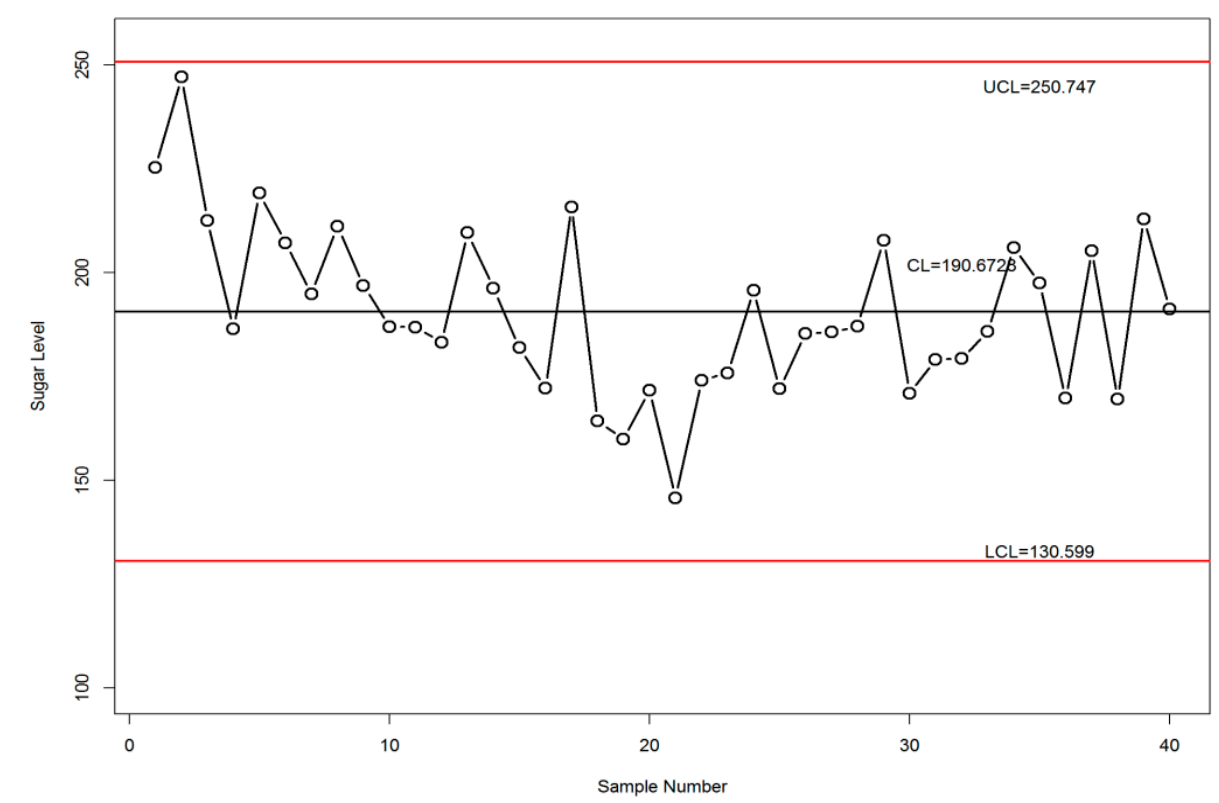

Figure 2. The Shewhart mean control chart for the glucose levels in type II diabetic patients.

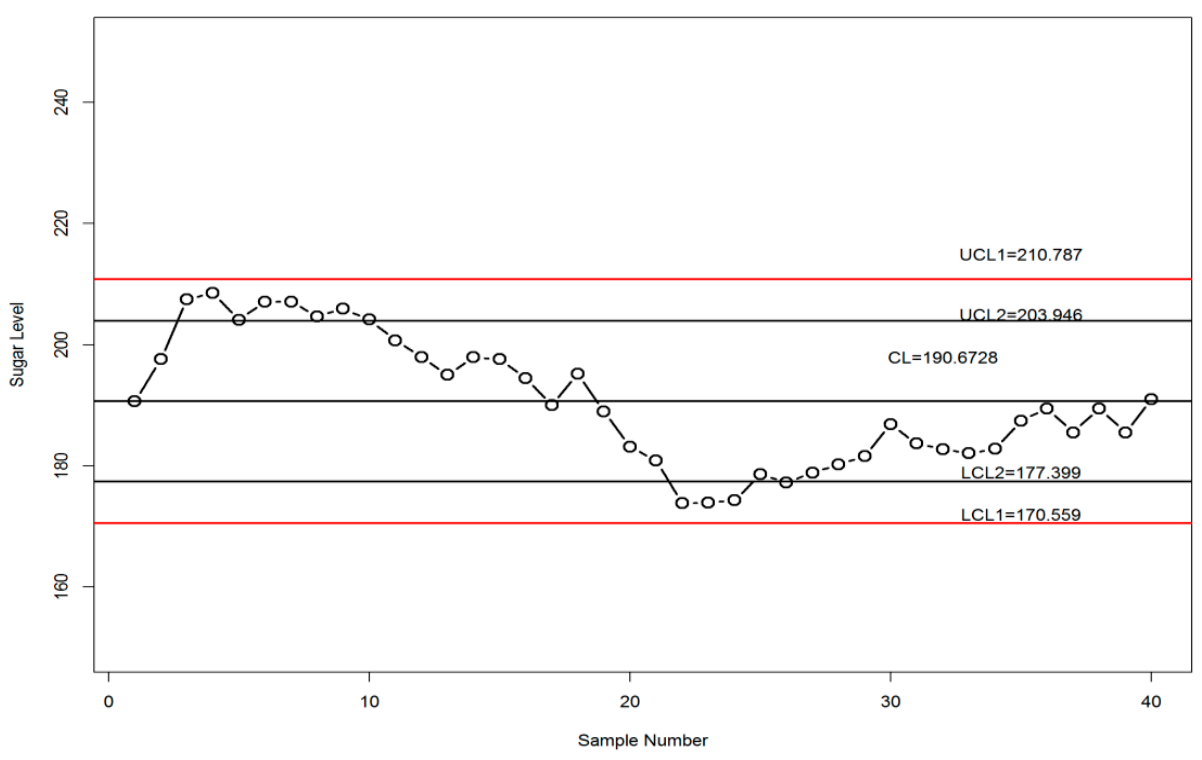

Figure 3. The proposed control chart for the glucose levels in type II diabetic patients.

The performance of the proposed control chart for the monitoring diabetic levels is also discussed with the help of simulated data. Diabetics should aim for an SD of one-third of their mean blood sugar. Therefore, if your mean blood sugar were $120 \mathrm{mg} / \mathrm{dL}$, you would want your standard deviation to be no more than $40 \mathrm{mg} / \mathrm{dL}$, or one-third of the mean (for more information, (see [32]). In simulation study first 20 observation each of size 10 is generated from in control process with mean 120 and standard deviation of 40 and next 20 are generated with a shift in mean as $120+c \mathrm{SD}$, where $c=0.10$. The sugar levels of 40 patients of size 10 are plotted in Figures 4 and 5. From Figure 5, it can be noted that the proposed chart clearly indicates that sugar level of the patient has been shifted and out-of-control 
while Figure 4, which is traditional Shewhart chart, shows that sugar level is in control and the medical advisor should take no action.

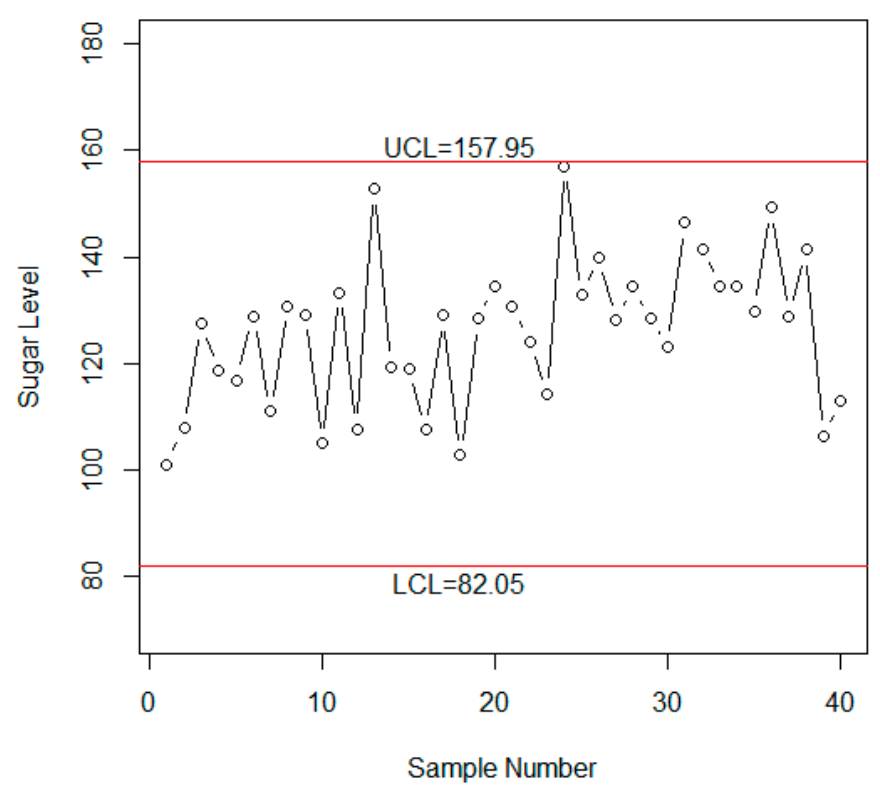

Figure 4. The Shewhart chart for simulated data.

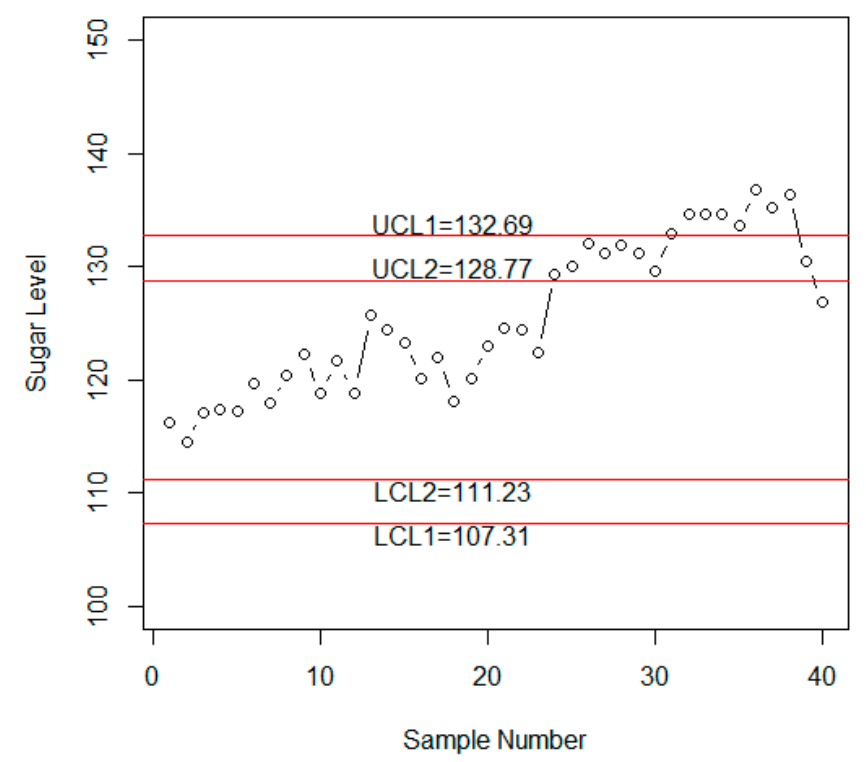

Figure 5. The proposed chart for simulated data when $\lambda=0.20$.

\section{Conclusions and Recommendations}

The monitoring of glucose levels in type II diabetic patients through the traditional Shewhart control chart is unable to detect a shift in the sugar level, which may cause of series diseases associated with sugar such as damage of kidneys, heart attack, and blood pressure. The proposed control chart was able to diagnose the shift in sugar level of patients as compared to Shewhart control chart and, thus, help the medical advisor to take on-time action to bring back the sugar level to the normal range. Therefore, the use of the proposed control chart in the healthcare issues will be helpful for strict monitoring of glucose levels in type II diabetic patients as compared to existing charts. The proposed control chart also directs the medical advisor to take another blood sample from the patient, in case a using single blood sample information. 
Author Contributions: Conceived and designed the experiments: M.A., G.S.R., N.K. and F.A.A.-A.; performed the experiments: M.A., G.S.R. and N.K.; analyzed the data: M.A., G.S.R. and N.K.; contributed reagents/materials/ analysis tools: M.A.; wrote the paper: M.A. and G.S.R.

Funding: This article was funded by the Deanship of Scientific Research (DSR) at King Abdulaziz University, Jeddah. The authors, therefore, acknowledge with thanks DSR technical and financial support.

Acknowledgments: The authors are deeply thankful to the editor and reviewers for their valuable suggestions to improve the quality of this manuscript.

Conflicts of Interest: The authors declare no conflict of interest regarding this paper.

\section{References}

1. Benneyan, J.C. Statistical quality control methods in infection control and hospital epidemiology, part II: Chart use, statistical properties, and research issues. Infect. Control Hosp. Epidemiol. 1998, 19, $265-282$. [CrossRef] [PubMed]

2. Shewhart, W.A. Economic Control of Quality of Manufactured Product; ASQ Quality Press: Milwaukee, WI, USA, 1931.

3. Woodall, W.H.; Mohammed, M.A.; Lucas, J.M.; Watkins, R. The Use of Control Charts in Health-Care and Public-Health Surveillance/Discussion/Discussion/Discussion/Discussion/Discussion/Discussion/Rejoinder. J. Qual. Technol. 2006, 38, 89-104. [CrossRef]

4. Aslam, M.; Azam, M.; Jun, C.-H. New attributes and variables control charts under repetitive sampling. Ind. Eng. Manag. Syst. 2014, 13, 101-106. [CrossRef]

5. Benneyan, J.C. Statistical Quality Control Methods in Infection Control and Hospital Epidemiology, Part I Introduction and Basic Theory. Infect. Control Hosp. Epidemiol. 1998, 19, 194-214. [CrossRef] [PubMed]

6. Thor, J.; Lundberg, J.; Ask, J.; Olsson, J.; Carli, C.; Härenstam, K.P.; Brommels, M. Application of statistical process control in healthcare improvement: Systematic review. Qual. Saf. Health Care 2007, 16, 387-399. [CrossRef]

7. Noyez, L. Control charts, Cusum techniques and funnel plots. A review of methods for monitoring performance in healthcare. Interact. Cardiovasc. Thorac. Surg. 2009, 9, 494-499. [CrossRef] [PubMed]

8. Smith, I.R.; Garlick, B.; Gardner, M.A.; Brighouse, R.D.; Foster, K.A.; Rivers, J.T. Use of graphical statistical process control tools to monitor and improve outcomes in cardiac surgery. Heart Lung Circ. 2013, 22, 92-99. [CrossRef]

9. Spiegelhalter, D.; Sherlaw-Johnson, C.; Bardsley, M.; Blunt, I.; Wood, C.; Grigg, O. Statistical methods for healthcare regulation: Rating, screening and surveillance. J. R. Stat. Soc. Ser. A (Stat. Soc.) 2012, 175, 1-47. [CrossRef]

10. Carey, R.G.; Stake, L.V. Improving Healthcare with Control Charts: Basic and Advanced SPC Methods and Case Studies; ASQ Quality Press: Milwaukee, WI, USA, 2003.

11. Woodall, W.H.; Spitzner, D.J.; Montgomery, D.C.; Gupta, S. Using control charts to monitor process and product quality profiles. J. Qua. Technol. 2004, 36, 309-320. [CrossRef]

12. Winkel, P.; Zhang, N.F. Statistical Development of Quality in Medicine; John Wiley \& Sons: Hoboken, NJ, USA, 2007; Volume 62.

13. Faltin, F.; Kenett, R.S.; Ruggeri, F. Statistical Methods in Healthcare; John Wiley \& Sons: Hoboken, NJ, USA, 2012.

14. Morton, A.; Whitby, M.; Tierney, N.; Sibanda, N.; Mengersen, K. Statistical Methods for Hospital Monitoring; Wiley Online Library: Hoboken, NJ, USA, 2013.

15. Beck, M.; Melo, S. Quality Management and Managerialism in Healthcare: A Critical Historical Survey; Springer: Berlin, Germany, 2014.

16. Mohammed, M.A.; Worthington, P. Why traditional statistical process control charts for attribute data should be viewed alongside an xmr-chart. BMJ Qual. Saf. 2013, 22, 263-269. [CrossRef]

17. Mohammed, M.A.; Panesar, J.S.; Laney, D.B.; Wilson, R. Statistical process control charts for attribute data involving very large sample sizes: A review of problems and solutions. BMJ Qual. Saf. 2013. [CrossRef] [PubMed]

18. Neuburger, J.; Walker, K.; Sherlaw-Johnson, C.; van der Meulen, J.; Cromwell, D.A. Comparison of control charts for monitoring clinical performance using binary data. BMJ Qual. Saf. 2017. [CrossRef] [PubMed] 
19. Cappon, G.; Acciaroli, G.; Vettoretti, M.; Facchinetti, A.; Sparacino, G. Wearable continuous glucose monitoring sensors: A revolution in diabetes treatment. Electronics 2017, 6, 65. [CrossRef]

20. Dong, Y.; Hedayat, A.; Sinha, B. Surveillance strategies for detecting changepoint in incidence rate based on exponentially weighted moving average methods. J. Am. Stat. Assoc. 2008, 103, 843-853. [CrossRef]

21. Sherman, R.E. Design and evaluation of a repetitive group sampling plan. Technometrics 1965, 7, 11-21. [CrossRef]

22. Abbas, N.; Riaz, M.; Does, R.J. Enhancing the performance of EWMA charts. Qual. Reliab. Eng. Int. 2011, 27, 821-833. [CrossRef]

23. Ahmad, L.; Aslam, M.; Jun, C.-H. Designing of X-bar control charts based on process capability index using repetitive sampling. Trans. Inst. Meas. Control 2014, 36, 367-374. [CrossRef]

24. Aslam, M.; Khan, N.; Azam, M.; Jun, C.-H. Designing of a new monitoring t-chart using repetitive sampling. Inf. Sci. 2014, 269, 210-216. [CrossRef]

25. Aslam, M.; Azam, M.; Jun, C.-H. A new exponentially weighted moving average sign chart using repetitive sampling. J. Process Control 2014, 24, 1149-1153. [CrossRef]

26. Al-Nuaim, A.A.; Al-Nakeeb, Y.; Lyons, M.; Al-Hazzaa, H.M.; Nevill, A.; Collins, P.; Duncan, M.J. The prevalence of physical activity and sedentary behaviours relative to obesity among adolescents from Al-Ahsa, Saudi Arabia: Rural versus urban variations. J. Nutr. Metab. 2012, 2012, 417589. [CrossRef]

27. Rathmann, W.; Giani, G. Global prevalence of diabetes: Estimates for the year 2000 and projections for 2030. Diabetes Care 2004, 27, 2568-2569. [CrossRef] [PubMed]

28. Rasheed, P. Perception of body weight and self-reported eating and exercise behaviour among obese and non-obese women in Saudi Arabia. Public Health 1998, 112, 409-414. [CrossRef]

29. Al-Baghli, N.A.; Al-Ghamdi, A.J.; Al-Turki, K.A.; El-Zubaier, A.G.; Al-Ameer, M.M.; Al-Baghli, F.A. Overweight and obesity in the eastern province of Saudi Arabia. Saudi Med. J. 2008, 29, 1319-1325. [PubMed]

30. American Diabetes Association. Standards of medical care in diabetes-2010. Diabetes Care 2010, 33, S11-S61. [CrossRef] [PubMed]

31. Alqurashi, K.A.; Aljabri, K.S.; Bokhari, S.A. Prevalence of diabetes mellitus in a Saudi community. Ann. Saudi Med. 2011, 31, 19-23. [CrossRef] [PubMed]

32. Standard Deviation Buzz. Available online: http://www.healthline.com/diabetesmine/standard_deviat\#1 (accessed on 25 November 2018). 